\title{
Semi-elemental versus polymeric formula for enteral nutrition in brain-injured critically ill patients: a randomized trial
}

\author{
Laurent Carteron ${ }^{1,2^{*}}$ (C) Emmanuel Samain ${ }^{1,2}$, Hadrien Winiszewski ${ }^{2,3}$, Gilles Blasco ${ }^{1}$, Anne-Sophie Balon ${ }^{1}$, \\ Camille Gilli ${ }^{1}$, Gael Piton ${ }^{2,3}$, Gilles Capellier ${ }^{2,3}$, Sebastien Pili-Floury ${ }^{1,2}$ and Guillaume Besch ${ }^{1,2}$
}

\begin{abstract}
Background: The properties of semi-elemental enteral nutrition might theoretically improve gastrointestinal tolerance in brain-injured patients, known to suffer gastroparesis. The purpose of this study was to compare the efficacy and tolerance of a semi-elemental versus a polymeric formula for enteral nutrition (EN) in brain-injured critically ill patients.

Methods: Prospective, randomized study including brain-injured adult patients [Glasgow Coma Scale (GCS) $\leq 8$ ] with an expected duration of mechanical ventilation $>48 \mathrm{~h}$. Intervention: an enteral semi-elemental (SE group) or polymeric (P group) formula. EN was started within $36 \mathrm{~h}$ after admission to the intensive care unit and was delivered according to a standardized nurse-driven protocol. The primary endpoint was the percentage of patients who received both $60 \%$ of the daily energy goal at 3 days and 100\% of the daily energy goal at 5 days after inclusion. Tolerance of EN was assessed by the rate of gastroparesis, vomiting and diarrhea.

Results: Respectively, 100 and 95 patients were analyzed in the SE and P groups: Age (57[44-65] versus 55[40-65] years) and GCS (6[3-7] versus 5[3-7]) did not differ between groups. The percentage of patients achieving the primary endpoint was similar (46\% and 48\%, respectively; relative risk (RR) [95\% confidence interval $(C \mathrm{Cl})]=1.05(0.78-1.42)$; $p=0.73)$. The mean daily energy intake was, respectively, $20.2 \pm 6.3$ versus $21.0 \pm 6.5 \mathrm{kcal} / \mathrm{kg} /$ day $(p=0.42)$. Protein intakes were $1.3 \pm 0.4$ versus $1.1 \pm 0.3 \mathrm{~g} / \mathrm{kg} /$ day $(p<0.0001)$. Respectively, $18 \%$ versus $12 \%$ patients presented gastroparesis $(p=0.21)$, and $16 \%$ versus $8 \%$ patients suffered from diarrhea $(p=0.11)$. No patient presented vomiting in either group.
\end{abstract}

Conclusion: Semi-elemental compared to polymeric formula did not improve daily energy intake or gastrointestinal tolerance of enteral nutrition.

Trial registration: EudraCT/ID-RCB 2012-A00078-35 (registered January 17, 2012).

Keywords: Nutrition, Semi-elemental, Brain injury, Critically ill

*Correspondence: Icarteron@chu-besancon.fr

${ }^{1}$ Department of Anesthesiology and Intensive Care Medicine, University Hospital of Besancon, 3 bvd Alexander Fleming, 25000 Besancon, France

Full list of author information is available at the end of the article

\section{Background}

Brain-injured critically ill patients admitted to the intensive care unit (ICU) suffer an increased metabolic rate and protein catabolism, leading to a high risk of energy and protein deficits [1-3]. Both are associated with a higher rate of infectious complications, prolonged ICU and hospital length of stay, unfavorable neurological outcome and higher mortality [2, 4]. Early enteral nutrition 
(EN) is recommended to improve outcome and should be initiated within $48 \mathrm{~h}$ after admission to the ICU in hemodynamically stable patients [5]. Despite published guidelines, brain-injured critically ill patients are commonly underfed and receive inadequate intake of both energy and protein [4]. Among the various reasons that have been advanced to explain this is intolerance of EN, related to impaired gastrointestinal mobility, which is common in brain-injured critically ill patients [4]. Indeed, gastroparesis and diarrhea during EN have been reported in, respectively, $20 \%$ and $70 \%$ of brain-injured critically ill patients [6, 7]. Gastroparesis and diarrhea might alter nutrient absorption and contribute to inadequate energy and protein intake, and could lead physicians to consider interrupting EN [4].

The prescription of a standard isotonic polymeric formula is recommended as the first-choice solution in unselected critically ill patients requiring EN, considering its cost-effectiveness compared to semi-elemental formula [5, 8]. However, semi-elemental solutions containing small peptides and predominantly medium chain triglycerides (MCTs) might theoretically improve gastrointestinal tolerance [9-15]. Proteins hydrolyzed into peptides might facilitate gastric emptying, and the high proportion of MCTs might improve gastrointestinal tolerance and decrease the rate of diarrhea $[9,10,13-15]$. To date, the efficacy and tolerance of semi-elemental formulae have never been specifically addressed in braininjured critically ill patients.

The hypothesis of the present study was that gastrointestinal tolerance of semi-elemental formula would be better compared to a polymeric formula and would thus improve early energy and protein intake in brain-injured critically ill patients. The aim of the study was therefore to compare the efficacy and tolerance of a semi-elemental versus a polymeric formula in brain-injured critically ill patients.

\section{Methods}

\section{Study design}

We conducted a randomized single-center open-label superiority trial (EudraCT/ID-RCB 2012-A00078-35) in parallel groups, from June 2012 to February 2019 in the medical and surgical intensive care units of the University Hospital of Besancon (Besancon, France). The study protocol was approved by the Institutional Review Board (CPP Est-II, University Hospital of Besancon no. 12/639), and by the French National Health Products Safety Agency (ANSM, Saint-Denis, France no. 2012-A0007835). The study was conducted in accordance with the French legislation on bioethics [16]. The results are reported in compliance with the Consolidated Standards of Reporting Trials (CONSORT) guidelines.

\section{Data and endpoint measures}

Demographic data, past medical history, Simplified Acute Physiology Score (SAPS) II score and Glasgow Coma Score (GCS) were recorded at admission to the ICU. Gastric residual volume was measured every $12 \mathrm{~h}$. The following data were collected every day during the study period: body weight, sedation (yes/no), catecholamine infusion (yes/no) and the total volume of EN administered. The daily ratio of volume of EN administered to the volume prescribed according to the protocol was calculated.

Blood levels of liver enzymes, albumin and prealbumin were measured at inclusion, at 5 and 10 days after inclusion.

The primary endpoint was the percentage of patients who received both $60 \%$ of the daily energy intake goal 3 days after inclusion and $100 \%$ of the daily energy intake goal 5 days after inclusion. These thresholds corresponded to the nutritional goals stipulated in published guidelines in force at the time of the study initiation $[17,18]$.

Secondary endpoints were the tolerance of EN, the nutritional impact of EN, morbidity at 28 days and mortality at 28 and 60 days. Tolerance was assessed by the rate of gastroparesis, vomiting and diarrhea and by the incidence of alteration of blood levels of liver enzymes. Gastroparesis was defined as a gastric residual volume $>500 \mathrm{ml}$, and diarrhea as more than 3 unusually loose or watery stools per day for 2 consecutive days. Alteration of blood levels of liver enzymes was defined as the occurrence of an abnormal value of aspartate aminotransferase (AST $>34$ IU/l) or alanine aminotransferase (ALT $>65 \mathrm{IU} / \mathrm{l}$ ) (alteration of transaminases), and/or the occurrence of an abnormal value of gamma-glutamyl transferase (GGT > 64 IU/l) (abnormal gamma-glutamyl transferase) during the study period. Nutritional impact was evaluated by the daily energy and protein intakes delivered and on the variation of blood albumin and prealbumin measured at baseline, at Day 5 and at Day 10 after inclusion. Morbidity events considered at 28 days were duration of invasive mechanical ventilation, the length of stay in the ICU and onset of pneumonia. Pneumonia was defined according to the French guidelines by the presence of: fever $>38.3{ }^{\circ} \mathrm{C}$ without any other cause, purulent sputum or tracheal aspiration, declining oxygenation or increased oxygen-requirement and new or progressive lung infiltrates on chest radiographs [19]. The reliability of all data collected was assessed by an independent data manager at the end of the study. 


\section{Study population}

All consecutive brain-injured critically ill patients admitted with an initial GCS $\leq 8$ and an expected duration of mechanical ventilation $>48 \mathrm{~h}$ were eligible. Exclusion criteria were: age $<18$ years, abdominal surgery during the 14 days prior to inclusion, hemodynamic instability within the 36 first hours in the ICU (defined as an increasing infusion rate of catecholamine, a norepinephrine infusion rate $\geq 3 \mathrm{mg} / \mathrm{h}$ or an epinephrine infusion rate $\geq 1 \mathrm{mg} / \mathrm{h}$ ), contraindication to semi-recumbent position or gastric tube insertion, pregnancy and/or breastfeeding, patient refusal and adults under legal protection. Written informed consent was obtained from a relative prior to inclusion. The deferred consent process was applied if proxies were not contactable at the time of inclusion.

\section{Randomization and study intervention}

Patients included in the study were randomly assigned within $36 \mathrm{~h}$ after ICU admission to either the polymeric or the semi-elemental group using a computer-generated randomization list (ratio 1:1; block size of 4). The polymeric group received a hypercaloric $(1.5 \mathrm{kcal} / \mathrm{ml})$ polymeric formula (Sondalis $\mathrm{HP}^{\circledR}$, Nestlé Healthcare Science, Vevey, Switzerland), including, per $100 \mathrm{ml}, 7.5 \mathrm{~g}$ of proteins, $5.8 \mathrm{~g}$ of lipids and $17.0 \mathrm{~g}$ of carbohydrates (osmolality: $310 \mathrm{mOsm} / \mathrm{L}$ ). The semi-elemental group received a hypercaloric $(1.5 \mathrm{kcal} / \mathrm{ml})$ semi-elemental formula (Peptamen $\mathrm{AF}^{\circledR}$, Nestlé Healthcare Science, Vevey, Switzerland), including, per $100 \mathrm{ml}, 9.4 \mathrm{~g}$ of proteins hydrolyzed into small peptides, $6.5 \mathrm{~g}$ of lipids and $13.5 \mathrm{~g}$ of carbohydrates (osmolality: $380 \mathrm{mOsm} / \mathrm{L}$ ). Ingredients and nutritional content of the EN solutions are detailed in "Appendix 1." Isocaloric and isovolumic solutions (polymeric or semi-elemental formula) were allocated using opaque envelopes. The solutions allocated by randomization were prescribed for the first 10 days of EN (study period). The investigators were unaware of the randomization block size. Since the packaging and the aspect of the polymeric and semi-elemental solutions were quite different, neither the investigators nor the caregivers were blinded to the treatment allocation. The allocated group was recorded in the patient's medical file and available to all the caregivers in charge of the patient.

EN was started within $36 \mathrm{~h}$ after admission in the ICU at $6 \mathrm{pm}$ in all patients and delivered continuously over $24 \mathrm{~h}$ using a pump via a gastric tube. EN was administered following the same standardized protocol in both groups (see "Appendix 2"). This protocol was implemented in the ICU in 2012 and complied with the guidelines in force at the time when the study started [17, 18]. In order to make this nurse-driven protocol easy to implement, the daily energy intake goal was either 1512 or $2268 \mathrm{kcal}$ so that the pump rate was a multiple of $21 \mathrm{ml} / \mathrm{h}$ (either $42 \mathrm{ml} / \mathrm{h}$, i.e., $1512 \mathrm{kcal} /$ day in males and females with an estimated ideal body weight using the Lorentz's formula $\leq 60 \mathrm{~kg}$; or $63 \mathrm{ml} / \mathrm{h}$, i.e., $2268 \mathrm{kcal}$ per day for the others). These two daily caloric intake goals were determined to deliver a daily amount of calories that was as close as possible to the target of $30 \mathrm{kcal} / \mathrm{kg}$ of ideal body weight. The initial pump rate was $21 \mathrm{ml} / \mathrm{h}$ and was adjusted every $12 \mathrm{~h}$ by steps of $21 \mathrm{ml} / \mathrm{h}$ according to the gastric residual volume, to reach the nutrition goal. If the gastric residual volume was $>500 \mathrm{ml}$ for more than $12 \mathrm{~h}$, the pump rate was decreased and the EN stopped if necessary. The EN was resumed at a pump rate of $21 \mathrm{ml} / \mathrm{h}$ as soon as the gastric residual volume was $\leq 500 \mathrm{ml}$ (see "Appendix 2"). If the patient vomited, EN was stopped for $12 \mathrm{~h}$ and resumed at a pump rate of $21 \mathrm{ml} / \mathrm{h}$. Three days of intravenous prokinetics (association of erythromycin $3 \mathrm{mg} / \mathrm{kg} 3$ times per day and metoclopramide $10 \mathrm{mg} 3$ times per day) were prescribed in case of gastroparesis and/or vomiting. In case of diarrhea, the treatments were: First, $500 \mathrm{ml}$ of normal saline was added to the EN solution for the next $24 \mathrm{~h}$ to increase sodium concentration in the digestive tract and the rate of EN was increased according to the protocol described above; if the symptoms persisted, the pump rate was decreased by $21 \mathrm{ml} / \mathrm{h}$ for the next $24 \mathrm{~h}$, and then, loperamide $4 \mathrm{mg}$ twice per day was started until disappearance of diarrhea [20]. EN was stopped if the patient needed to be transferred to the operating room, undergo diagnostic investigation out of the ICU or be extubated. EN was then resumed as soon as possible at the same rate as prior to discontinuation. EN was stopped when neurological recovery allowed for withdrawal of invasive mechanical ventilation and resumption of oral feeding. The study period ended when EN was stopped, if the patient was discharged from the ICU, or 10 days after randomization, whichever occurred first. Afterward, patients received standard EN if still required according to the routine protocol used in the ICU. During the study period, patients were sedated with midazolam and sufentanil when necessary. No patient was sedated with propofol.

\section{Statistical analysis}

The sample size calculation was based on a retrospective analysis of data recording sheets from patients admitted to our ICU who received the polymeric formula for EN following the same protocol (data not shown). The expected rate of patients included in the polymeric group who achieved the primary endpoint was $50 \%$. Considering an expected value of the primary endpoint of $70 \%$ in the semi-elemental group, at an $\alpha$ risk of 0.05 and $\beta$ risk 
of 0.20 , and a loss to follow-up rate of $10 \%, 103$ patients were required in each group.

The Shapiro-Wilk test was used to test the normality of the distribution of quantitative data. Continuous variables are expressed as mean \pm standard deviation, or median (interquartile range $25-75 \%$ ), as appropriate, and categorical variables as number (percentage). Intergroup comparisons were performed using the Chi-square or Fisher's exact test for qualitative variables and the Student $t$ or Mann-Whitney $U$ test for quantitative variables, as appropriate. Repeated measurements of daily energy and protein intakes, blood levels of albumin and prealbumin were compared between groups using repeated measure ANOVA. The analysis was neither adjusted nor stratified for additional variables. No subgroup analysis was performed. All statistical analyses were performed with SAS software, version 9.4 (SAS Institute Inc., USA), and the significance level was fixed at 0.05 .

\section{Results}

\section{Study population}

A total of 206 patients were included during the study period, and 100 and 95 patients were analyzed in the semi-elemental and polymeric groups, respectively. The reasons for exclusion are shown in the study flowchart in Fig. 1. The baseline characteristics of patients were similar between groups (Table 1 ). The daily caloric intake goals (either 1512 or $2268 \mathrm{kcal}$ per day) and the percentage of goal that was delivered each day in the two groups are presented in "Appendix 3." The daily energy and protein intake are presented in Fig. 2. Daily protein intake was significantly higher in the semi-elemental group during the study period ( $\mathrm{p}$-value for repeated measures ANOVA $=0.0067)$. The mean daily caloric and protein intake were, respectively, $20.2 \pm 6.3$ versus $21.0 \pm 6.5 \mathrm{kcal} / \mathrm{kg} /$ day (mean difference (MD) [95\% confidence interval $(\mathrm{CI})]=-0.7(-2.6$ to 1.1$) ; p=0.42)$ and $1.3 \pm 0.4$ versus $1.1 \pm 0.3 \mathrm{~g} / \mathrm{kg} /$ day [95\% confidence inter$\operatorname{val}(\mathrm{CI})]=0.2(0.1-0.3) ; p<0.0001)$ in the semi-elemental and polymeric groups.

\section{Primary endpoint}

Among the 195 patients analyzed, the primary endpoint did not differ significantly between groups (46 (46\%) versus 46 (48\%) patients, respectively, in the semi-elemental and polymeric groups; [relative risk (RR) $(95 \% \mathrm{CI})=1.05$ $(0.78-1.42) ; p=0.73])$. This result was not modified after exclusion of patients in whom EN had been discontinued before Day 3 (7 patients) and Day 5 (28 further patients) after inclusion because of early neurological recovery that enabled resumption of oral feeding. Among the 160 patients who were on EN for at least 5 days, the primary endpoint was met in $46(58 \%)$ versus 46 (57\%) patients, respectively, in the semi-elemental and polymeric groups $[R R(95 \% \mathrm{CI})=0.98(0.75-1.27) ; p=0.85]$. EN was discontinued for transfer to the operating room or for diagnostic investigation outside of the ICU in $14(14 \%)$ versus $11(12 \%)$ patients in the semi-elemental and polymeric groups, respectively $(p=0.61)$. The median time to administration of $100 \%$ of the target volume prescribed

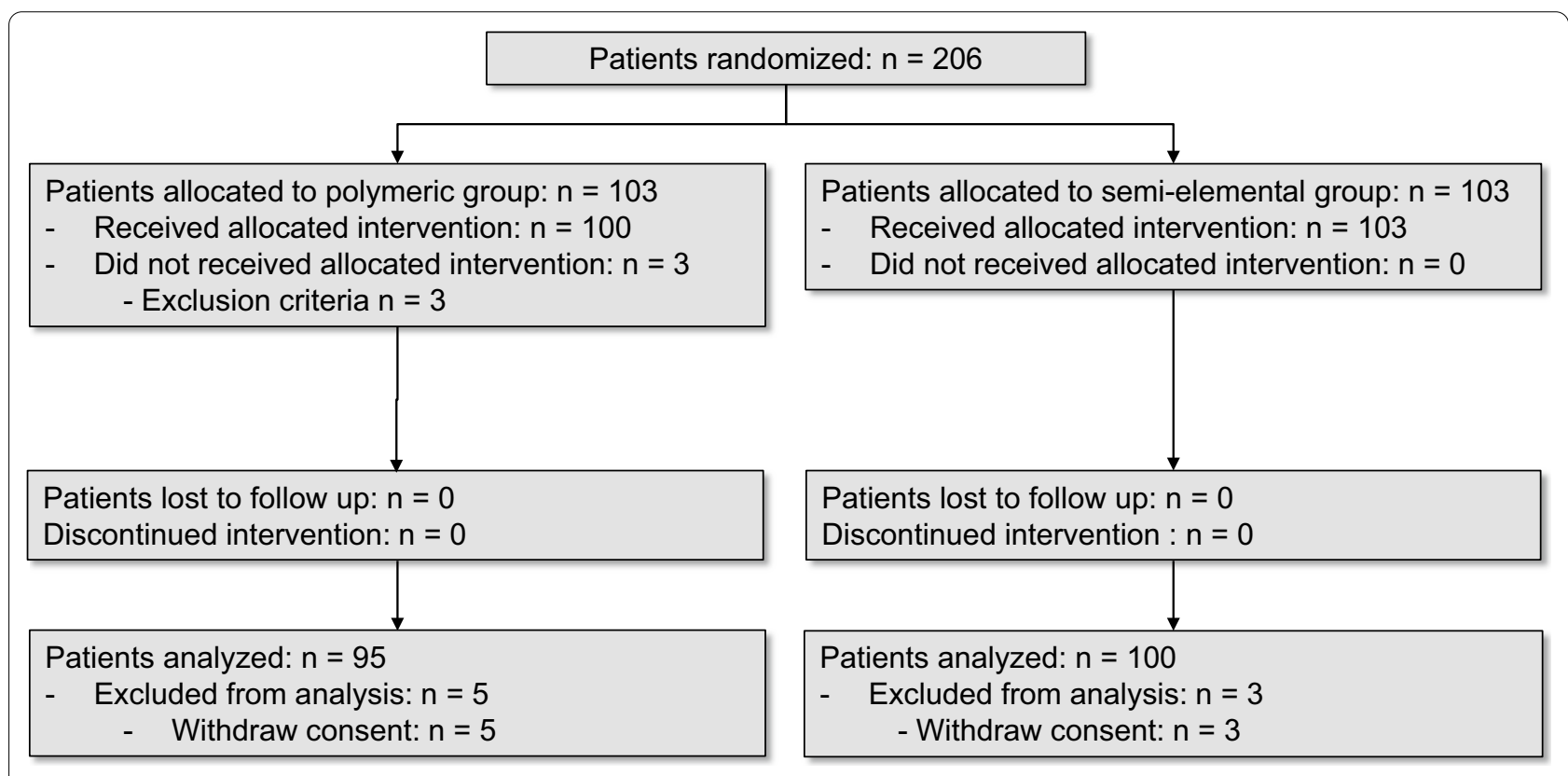

Fig. 1 Flowchart of patient inclusions according to the CONSORT (consolidated standards of reporting trials) statement 
Table 1 Baseline characteristics of patients in the semi-elemental and polymeric groups

\begin{tabular}{|c|c|c|c|}
\hline & $\begin{array}{l}\text { Semi-elemental group } \\
n=100 \text { patients }\end{array}$ & $\begin{array}{l}\text { Polymeric group } \\
n=95 \text { patients }\end{array}$ & $p$ \\
\hline Age (years) & $57[44-65]$ & 55 [40-65] & 0.75 \\
\hline Male $^{a}$ & $67(67)$ & $53(56)$ & 0.11 \\
\hline Ideal body weight (kg) & $65[58-70]$ & $64[56-70]$ & 0.45 \\
\hline Body mass index $\left(\mathrm{kg} \mathrm{m}^{-2}\right)$ & 26 [23-29] & 26 [23-29] & 0.63 \\
\hline SAPS II score at admission ${ }^{b}$ & $48 \pm 12$ & $49 \pm 13$ & 0.52 \\
\hline GCS at admission & $6[3-7]$ & $5[3-7]$ & 0.15 \\
\hline Type of brain injury ${ }^{a}$ & & & 0.50 \\
\hline Traumatic brain injury & $49(49)$ & $46(48)$ & \\
\hline Intracerebral hemorrhage & $13(13)$ & $11(12)$ & \\
\hline Subarachnoid hemorrhage & $21(21)$ & $29(31)$ & \\
\hline Stroke & $14(14)$ & $6(6)$ & \\
\hline Other & $3(3)$ & $3(3)$ & \\
\hline Duration of catecholamine support (days) & $1[0-3]$ & $2[0-3]$ & 0.72 \\
\hline Duration of sedation (days) & $1[0-3]$ & $2[0-3]$ & 0.28 \\
\hline
\end{tabular}

Data are median [interquartile range]; ideal body weight was calculated according to the Lorentz formula

GCS Glasgow Coma Scale, SAPS II Simplified Acute Physiological Score II, GCS Glasgow Coma Score

a Data are number of patients (percentage)

b Data are mean \pm standard deviation

according to the protocol after initiation of EN was 1 $[1-3]$ versus $1[1,2]$ days in the semi-elemental and polymeric groups, respectively $(p=0.07)$.

\section{Secondary endpoints}

Data on gastrointestinal tolerance, morbidity and mortality are reported in Table 2. The incidence of gastroparesis and diarrhea did not significantly differ between groups (Table 2). No patient in either group presented vomiting during the study period. Figure 3 shows the course of blood albumin and prealbumin over time, and it did not significantly differ between the groups.

\section{Discussion}

The results of this single-center randomized trial show that semi-elemental formula did not improve gastrointestinal tolerance of EN and early energy intake in braininjured critically ill patients compared to polymeric formula. Semi-elemental formula increased daily protein intake, but had no impact on blood levels of albumin or prealbumin.

Semi-elemental formulae appear to have no beneficial impact on outcome including gastrointestinal tolerance when prescribed in unselected ICU patients, and were shown to require a decrease of at least $7 \%$ in the number of cases of gastrointestinal intolerance in order to be costeffective in ICU patients $[8,21]$. Considering the lack of a clearly demonstrated clinical benefit, and the higher price compared to polymeric formula, the ESPEN guidelines recommend that semi-elemental formulae should not be prescribed as first-line EN solution in ICU patients, but deserve further investigation in patients at high risk of gastrointestinal dysfunction [18]. Brain-injured critically ill patients with intracranial hypertension are at high risk for gastroparesis [4]. Our primary physiological hypothesis was that proteins hydrolyzed into small peptides might promote gastric emptying in this population. Some studies have reported early functional and structural alteration of intestinal mucosa, including villous atrophy, in rat models of traumatic brain injury [22]. Semi-elemental formula has been reported to present nutritional and clinical benefits in nutritionally high-risk non-ICU patients suffering from illnesses that could lead to villous atrophy, such as Crohn's disease, short bowel syndrome or acute and chronic pancreatitis [9]. The present study is the first randomized controlled trial to specifically address the efficacy and tolerance of semi-elemental EN in brain-injured critically ill patients. Several mechanisms of impaired gastrointestinal function have been identified in this population [23]. This complex pathophysiology might explain the lack of beneficial impact of semi-elemental compared to polymeric formula on gastrointestinal tolerance observed in the present study. The higher fat and protein contents and the higher osmolality in the semi-elemental formula might be another explanation for the lack of difference between the two groups since fat, protein and osmolality could slow gastric emptying and osmolality could promote osmotic diarrhea [24-26]. 


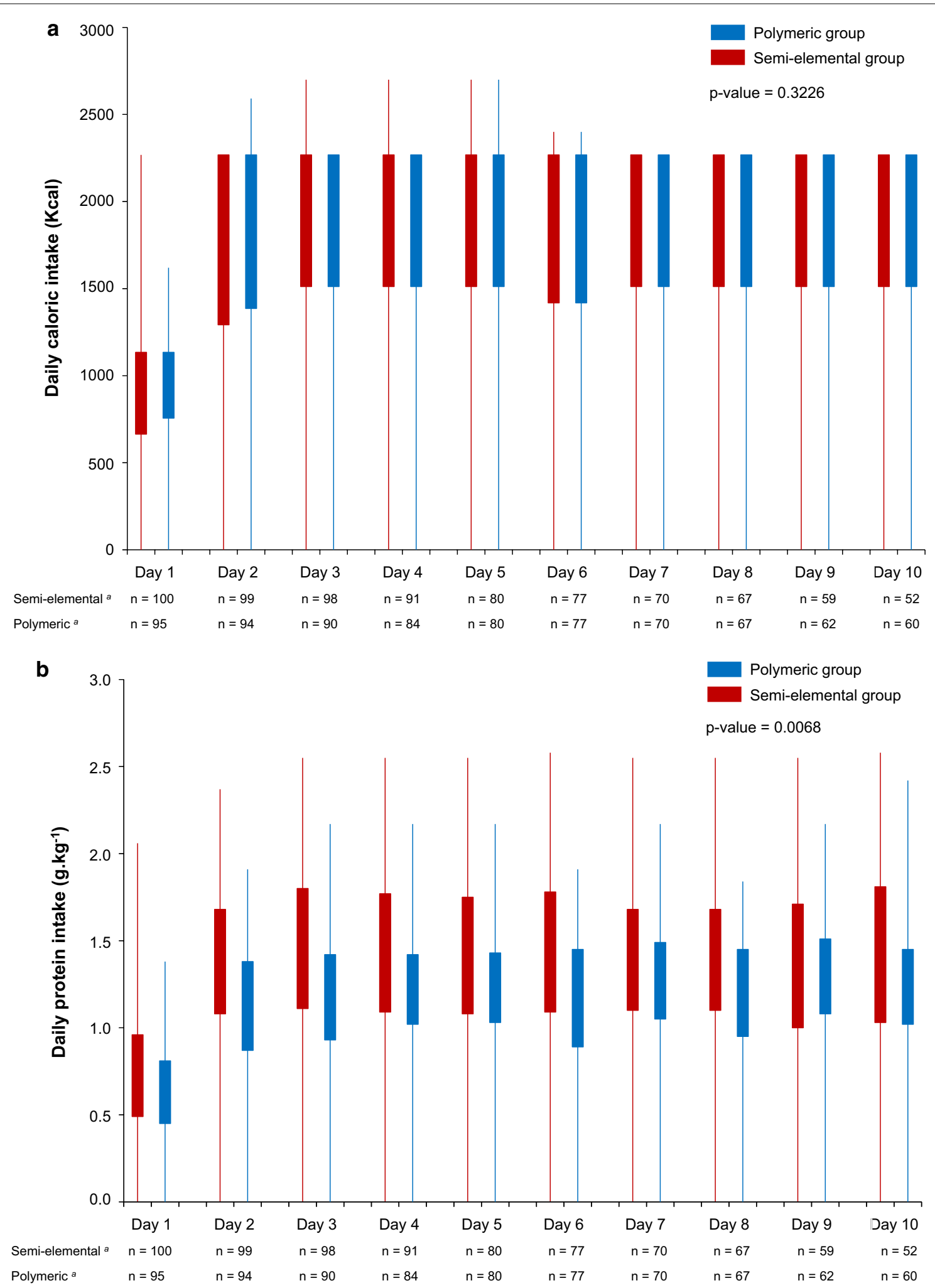

Fig. 2 Daily caloric (a) and protein (b) intake during the study period in the semi-elemental and polymeric groups. Box plots show interquartile

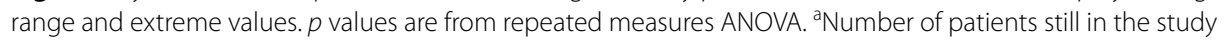


Table 2 Tolerance of enteral nutrition, morbidity and mortality in the semi-elemental and polymeric groups

\begin{tabular}{|c|c|c|c|c|}
\hline \multirow{2}{*}{$\begin{array}{l}\text { Variable } \\
\text { Gastrointestinal tolerance of enteral nutrition }\end{array}$} & \multicolumn{2}{|c|}{$\begin{array}{l}\text { Semi-elemental group } \\
n=100 \text { patients }\end{array}$} & \multirow[t]{2}{*}{$\begin{array}{l}\text { Polymeric group } \\
n=95 \text { patients }\end{array}$} & \multirow[t]{2}{*}{$p$ value } \\
\hline & & & & \\
\hline Gastroparesis & $18(18)$ & & $11(12)$ & 0.21 \\
\hline Requiring interruption of enteral nutrition & $6(6)$ & & $5(5)$ & 1.00 \\
\hline Diarrhea & $16(16)$ & & $8(8)$ & 0.11 \\
\hline Requiring addition of saline ${ }^{b}$ & $10(10)$ & & $1(1)$ & 0.01 \\
\hline Requiring loperamide ${ }^{b}$ & $4(4)$ & & $0(0)$ & 0.05 \\
\hline \multicolumn{5}{|l|}{ Alteration of blood levels of liver enzymes ${ }^{c}$} \\
\hline Alteration of transaminases & $13(13)$ & & $10(11)$ & 0.66 \\
\hline Abnormal gamma-glutamyl transferase & $23(23)$ & & $16(17)$ & 0.37 \\
\hline \multicolumn{5}{|l|}{ Morbidity within 28 days after inclusion } \\
\hline Length of mechanical ventilation (days) ${ }^{\mathrm{a}}$ & & $10[6-16]$ & $11[6-17]$ & 0.52 \\
\hline Length of stay in the ICU (days) ${ }^{\mathrm{a}}$ & & 14 [8-21] & $15[10-23]$ & 0.18 \\
\hline Pneumonia $^{d}$ & & $47(47)$ & $41(43)$ & 0.59 \\
\hline Mortality at 28 days & & $20(20)$ & $21(22)$ & 0.71 \\
\hline Mortality at 60 days & & $23(23)$ & $23(24)$ & 0.81 \\
\hline
\end{tabular}

Data are number of patients (percentage)

ICU intensive care unit; gastroparesis was defined as a gastric residual volume $>500 \mathrm{ml}$, and diarrhea as more than 3 unusually loose or watery stools per day for 2 consecutive days

a Data are median [interquartile range]

b According to the enteral nutrition protocol, in case of diarrhea, the treatments were: First, $500 \mathrm{ml}$ of normal saline was added to the enteral nutrition solution for the next $24 \mathrm{~h}$; if the symptoms persisted, the pump rate was decreased by $21 \mathrm{ml} / \mathrm{h}$ for the next $24 \mathrm{~h}$ and then loperamide $4 \mathrm{mg}$ twice per day was started until disappearance of diarrhea

c Alteration of transaminases was defined as abnormal value of aspartate aminotransferase (AST > 34 IU/I) or alanine aminotransferase (ALT > 65 IU/I). Abnormal gamma-glutamyl transferase was defined as abnormal value of gamma-glutamyl transferase (GGT > 64 IU/l)

d Pneumonia was defined by the presence of: fever $>38.3^{\circ} \mathrm{C}$ without any other cause, purulent sputum or tracheal aspiration, declining oxygenation or increased oxygen-requirement, and new or progressive lung infiltrates on chest radiographs [19]

In terms of advantages, the semi-elemental formula resulted in a significant increase in daily protein delivery compared to the polymeric formula. This increase simply resulted from the higher protein content of the semi-elemental solution. High protein intake might theoretically attenuate $\mathrm{ICU}$-acquired muscle weakness and improve long-term functional outcome by promoting protein synthesis and by preserving muscle mass [27]. Several observational studies have suggested that high protein intake could improve morbidity and mortality [28]. However, the relevance of high protein intake in ICU patients remains controversial, since no beneficial effect and even harmful effects were reported in other observational and randomized controlled studies [12, 29-33]. Nonetheless, the ESPEN guidelines recommend that $1.3 \mathrm{~g} / \mathrm{kg} /$ day of protein should be gradually delivered in critically ill patients [5]. However, reaching this target remains extremely challenging with standard solutions and requires very-high protein formula to avoid overfeeding while providing high protein intake [12]. Likewise, by promoting gut function and protein absorption, semi-elemental or elemental solutions should be considered in high protein intake strategies in ICU patients
[33, 34]. Moreover, beyond the consideration of protein intake, enteral formulae containing $100 \%$ of weighthydrolyzed protein have been reported to have beneficial anti-inflammatory effects in non-ICU elderly patients with acute ischemic stroke [35], whether these antiinflammatory effects could be observed in brain-injured critically patients, and whether they might improve clinical outcome has never been investigated.

Moreover, our hypothesis was that improved gastrointestinal tolerance would lead to an increase in caloric intake and to improved nutritional status, reflected by higher albumin and prealbumin blood levels. In fact, albumin and prealbumin are negative acute phase proteins and low values might result from a response to inflammation rather than an alteration in nutritional status [36]. This could explain the lack of difference in albumin and prealbumin blood levels between the two groups.

\section{Limitations of the study}

This single-center study was conducted in two independent ICUs, and it is uncertain that the same results would be observed using a different EN protocol. 
a

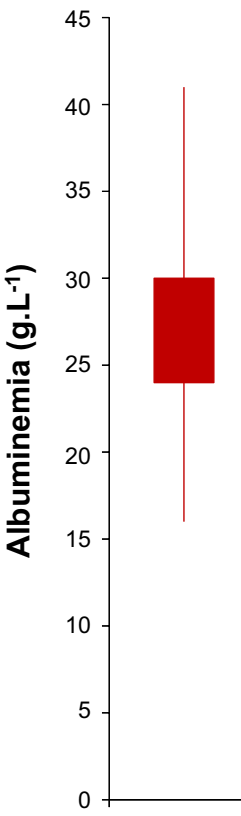

Polymeric group

Semi-elemental group

$p$-value $=0.4130$

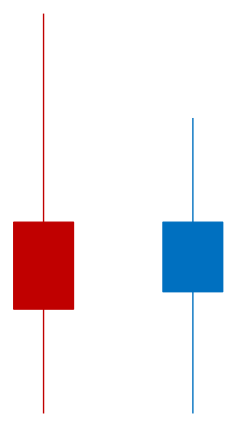

$\begin{array}{lccc} & \text { Baseline } & \text { Day } 5 & \text { Day } 10 \\ \text { Semi-elemental }^{a} & \mathrm{n}=100 & \mathrm{n}=80 & \mathrm{n}=52 \\ \text { Polymeric }^{a} & \mathrm{n}=95 & \mathrm{n}=80 & \mathrm{n}=60\end{array}$

b

b
40

35

35

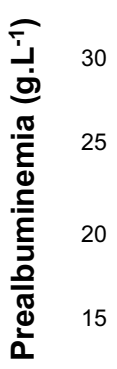

10

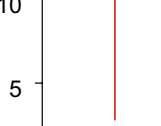

.

0

$$
\text { Baseline }
$$

Semi-elemental ${ }^{a}$

$\mathrm{n}=100$

Polymeric ${ }^{a}$

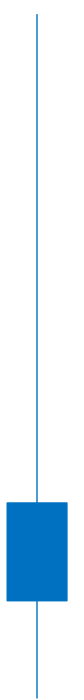

Polymeric group

Semi-elemental group

$p$-value $=0.4353$

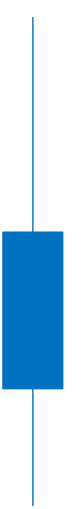

Fig. 3 Blood levels of albumin (a) and prealbumin (b) at baseline, Day 5 and Day 10 after inclusion in the semi-elemental and polymeric groups. Box plots show interquartile range and extreme values. P-values are from repeated measures ANOVA. ${ }^{2}$ Number of patients still in the study 
Furthermore, two daily caloric intake goals instead of individual calculations were used. Recent guidelines indeed recommended adjusting daily energy intake to energy expenditure using indirect calorimetry, but this recommendation was applied in only $1 \%$ of patients in an international observational study including 1045 braininjured patients from 341 ICUs $[4,5,18]$. Moreover, the EN protocol used in the present study did not lead to patient underfeeding and about $25 \%$ of patients in the two groups were slightly overfed, i.e., had an energy administration between 110 and $120 \%$ of the defined target. Nevertheless, the present study aimed to compare the gastrointestinal tolerance of two different enteral nutrition formula rather than to assess the EN protocol. In fact, despite using a different protocol, the incidence of gastroparesis was similar to that reported in previously published studies $[4,6]$, with a lower rate of patients presenting diarrhea. This could be explained by the heterogeneity in the definition of diarrhea across the different studies. Finally, the primary endpoint was not a hard endpoint such as mortality, as in most previously published randomized controlled trials of nutritional therapy conducted in critically ill patients [37].

\section{Conclusion}

Semi-elemental compared to polymeric formula did not improve gastrointestinal tolerance of enteral nutrition and early caloric intake in brain-injured critically ill patients. These results suggest that standard isotonic polymeric formula might be the first-choice solution in brain-injured critically ill patients requiring EN supports.

\section{Abbreviations}

EN: Enteral nutrition; GCS: Glasgow Coma Score; Gl: Gastrointestinal; ICU: Intensive care unit; MCTs: Medium chain triglycerides; SE: Semi-elemental.

\section{Acknowledgements}

The authors want to thank respectfully Prof. Mette M. Berger, from the Lausanne University Hospital, Lausanne, Switzerland, for discussion about the results. They also warmly thank Gaëlle Amiotte and Lucie Vettoretti for their help in conducting this study.

\section{Authors' contributions}

$L C, E S, G B, A B$, SPF and GBe designed the study. LC, HW, GB, AB, CG, GP, SPF and $G B$ e recruited the patients. $L C, G B, A B$ and $C G$ acquired the data. $L C$ and GBe analyzed and interpreted the data. LC and Gbe drafted the first manuscript. All authors read and approved the final manuscript.

\section{Funding}

The work was not funded by National Institutes of Health $(\mathrm{NIH})$, Howard Hughes Medical Institute (HHMI), Medical Research Council (MRC), and/or Wellcome Trust. The work was not supported by official funding or a grant. The financial cost of the study was supported by the Department of Anesthesiology and Intensive Care Medicine, 3 Bvd Alexander Fleming, University Hospital of Besancon, F-25000 Besancon, France.

\section{Availability of data and materials}

The datasets used and/or analyzed during the current study are available from the corresponding author on reasonable request.

\section{Ethics approval and consent to participate}

The study protocol was approved by the Institutional Review Board (CPP Est-II, University Hospital of Besancon no. 12/639) and by the French National Health Products Safety Agency (ANSM, Saint-Denis, France no. 2012-A00078-35). Written informed consent was obtained from a relative prior to inclusion. The deferred consent process was applied if proxies were not contactable at the time of inclusion.

\section{Consent for publication \\ Not applicable.}

\section{Competing interests}

The authors declare that they have no competing interests.

\section{Author details}

${ }^{1}$ Department of Anesthesiology and Intensive Care Medicine, University Hospital of Besancon, 3 bvd Alexander Fleming, 25000 Besancon, France.

${ }^{2}$ EA3920, University of Franche Comté, Besancon, France. ${ }^{3}$ Medical Intensive Care Unit, University Hospital of Besancon, Besancon, France.

\section{Appendix 1}

\section{See Table 3.}


Table 3 Ingredients and nutritional content of Peptamen AF and Sondalis HP

\begin{tabular}{|c|c|c|c|c|}
\hline \multirow[t]{2}{*}{ Infusion rate } & \multicolumn{2}{|c|}{ Peptamen AF } & \multicolumn{2}{|c|}{ Sondalis HP } \\
\hline & $42 \mathrm{ml} / \mathrm{h}$ & $63 \mathrm{ml} / \mathrm{h}$ & $42 \mathrm{ml} / \mathrm{h}$ & $63 \mathrm{ml} / \mathrm{h}$ \\
\hline Volume (ml) & 1008 & 1512 & 1008 & 1512 \\
\hline Osmolality (mOsm/L) & 380 & & 310 & \\
\hline Energy (kcal) & 1512 & 2268 & 1512 & 2268 \\
\hline Proteins & 94.8 & 142.1 & 75.6 & 113.4 \\
\hline \multicolumn{4}{|l|}{ of which: } & 257.0 \\
\hline Sugars & 14.1 & 21.2 & 19.2 & 28.7 \\
\hline \multicolumn{4}{|l|}{ of which: } & 87.7 \\
\hline Saturates & 38.3 & 57.5 & 32.3 & 48.4 \\
\hline Monounsaturates & 6.6 & 9.8 & 12.1 & 18.1 \\
\hline Polyunsaturates & 10.9 & 16.3 & 13.1 & 19.7 \\
\hline MCT (g) & 34.3 & 51.4 & 27.2 & 40.8 \\
\hline Omega-3 (g) & 3.6 & 5.4 & 2.9 & 4.4 \\
\hline Omega-6 (g) & 8.3 & 12.4 & 7.0 & 10.4 \\
\hline Fibers (g) & 0 & 0 & 0 & 0 \\
\hline Salt (g) & 2.5 & 3.8 & 2.0 & 3.0 \\
\hline \multicolumn{5}{|l|}{ Minerals (mg) } \\
\hline Sodium (g) & 1.0 & 1.5 & 0.8 & 1.2 \\
\hline Chloride (g) & 0.8 & 1.2 & 1.3 & 2.0 \\
\hline Potassium (g) & 2.3 & 3.5 & 1.8 & 2.7 \\
\hline Calcium (g) & 1.0 & 1.5 & 0.9 & 1.4 \\
\hline Phosphorus (g) & 0.8 & 1.3 & 0.8 & 1.3 \\
\hline Magnesium (g) & 0.3 & 0.5 & 0.2 & 0.3 \\
\hline Iron (mg) & 16.1 & 24.2 & 12.1 & 18.1 \\
\hline Zinc (mg) & 15.1 & 22.7 & 12.1 & 18.1 \\
\hline Copper (mg) & 1.8 & 2.7 & 1.2 & 1.8 \\
\hline lodine $(\mu \mathrm{g})$ & 201.6 & 302.4 & 121.0 & 181.4 \\
\hline Selenium $(\mu \mathrm{g})$ & 100.8 & 151.2 & 60.5 & 90.7 \\
\hline Manganese (mg) & 3.4 & 5.1 & 2.0 & 3.0 \\
\hline Chromium ( $\mu \mathrm{g})$ & 75.6 & 113.4 & 60.5 & 90.7 \\
\hline Molybdenum ( $\mu \mathrm{g})$ & 181.4 & 272.2 & 90.7 & 136.1 \\
\hline Fluoride (mg) & 1.6 & 2.4 & 0.9 & 1.4 \\
\hline \multicolumn{5}{|l|}{ Vitamins } \\
\hline $\mathrm{A}(\mu \mathrm{g})$ & 1713.6 & 2570.4 & 1038.2 & 1557.4 \\
\hline$D(\mu g)$ & 17.1 & 25.7 & 16.1 & 24.2 \\
\hline $\mathrm{K}(\mu \mathrm{g})$ & 99.8 & 149.7 & 83.7 & 125.5 \\
\hline$C(\mathrm{mg})$ & 181.4 & 272.2 & 110.9 & 166.3 \\
\hline B1 (mg) & 2.8 & 4.2 & 1.7 & 2.6 \\
\hline B2 (mg) & 2.2 & 3.3 & 2.2 & 3.3 \\
\hline B6 (mg) & 2.9 & 4.4 & 2.5 & 3.8 \\
\hline Niacin (mg) & 12.1 & 18.1 & 9.1 & 13.6 \\
\hline Folic acid ( $\mu \mathrm{g})$ & 403.2 & 604.8 & 343.7 & 514.1 \\
\hline $\mathrm{B} 12(\mu \mathrm{g})$ & 4.5 & 6.8 & 4.0 & 6.0 \\
\hline Pantothenic acid (mg) & 9.5 & 14.2 & 7.1 & 10.6 \\
\hline Biotin $(\mu \mathrm{g})$ & 54.4 & 81.6 & 43.3 & 65.0 \\
\hline$E(m g)$ & 29.2 & 43.8 & 21,2 & 31.8 \\
\hline
\end{tabular}

MCT medium-chain triglyceride 


\section{Appendix 2}

\section{See Fig. 4.}

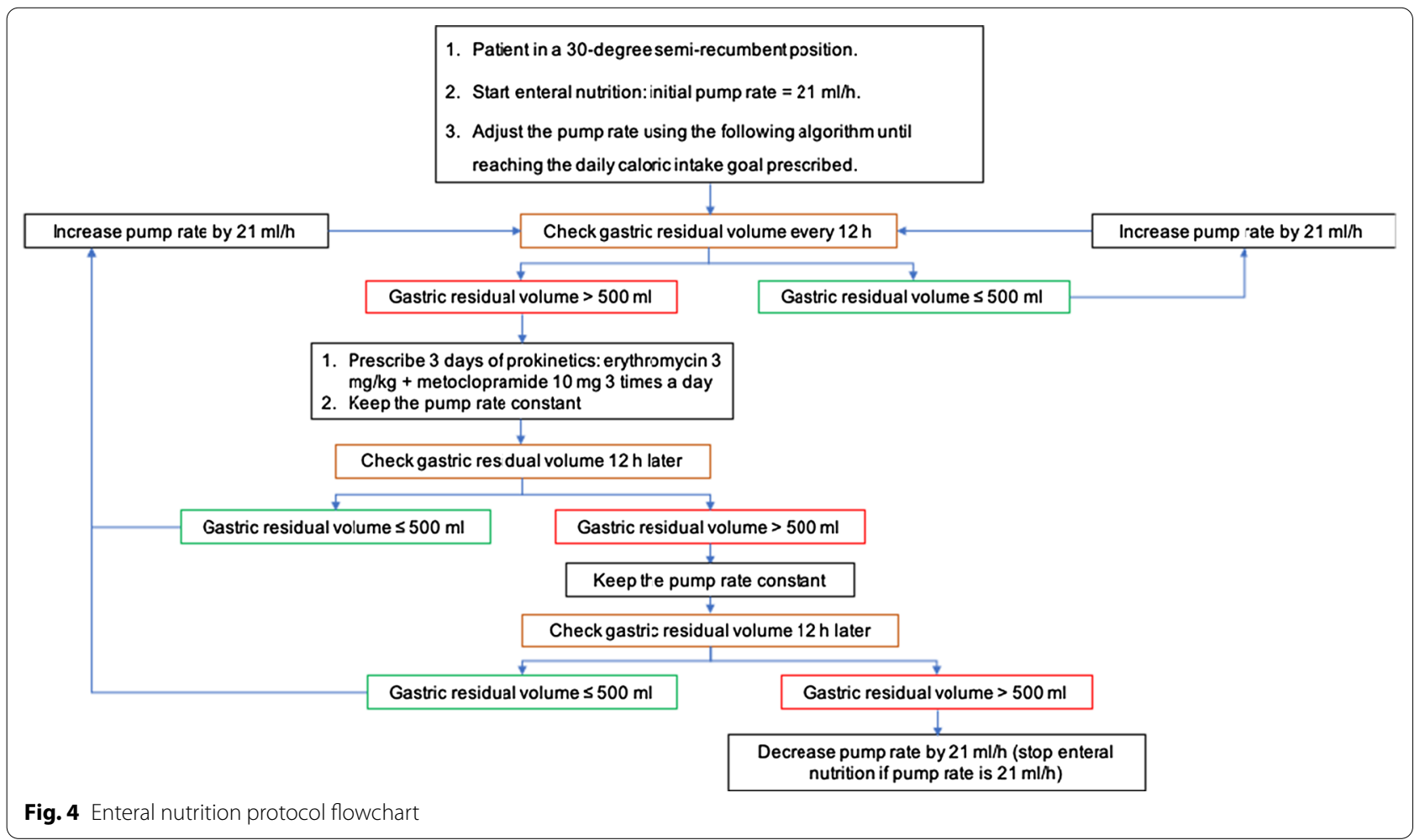

\section{Appendix 3}

\section{See Table 4.}

Table 4 Daily caloric intake goals and percentage of goal delivered in the semi-elemental and polymeric groups

\begin{tabular}{lll}
\hline & $\begin{array}{l}\text { Semi-elemental group } \\
\boldsymbol{n = 1 0 0} \text { patients }\end{array}$ & $\begin{array}{l}\text { Polymeric group } \\
\boldsymbol{n} \mathbf{9} \text { patients }\end{array}$ \\
\hline Daily caloric intake goal & & $32(34)$ \\
1512 kcal per day & $37(37)$ & $63(66)$ \\
2268 kcal per day & $63(63)$ & $50[38-50]$ \\
Percentage of daily caloric goal delivered ${ }^{a}$ & & $98[67-100]$ \\
Day 1 & $50[29-63]$ & $100[78-100]$ \\
Day 2 & $100[67-100]$ & $100[75-100]$ \\
Day 3 & $100[70-100]$ & $100[82-100]$ \\
Day 4 & $100[68-100]$ & $100[73-100]$ \\
Day 5 & $100[73-100]$ & $100[84-100]$ \\
Day 6 & $100[75-100]$ & $100[84-100]$ \\
Day 7 & $100[79-100]$ & $100[92-100]$ \\
Day 8 & $100[75-100]$ & $100[83-100]$ \\
Day 9 & $100[75-100]$ & \\
Day 10 & $100[67-100]$ & \\
\hline
\end{tabular}

Data are number of patients (percentage)

a Data are median [interquartile range] 
Received: 23 October 2020 Accepted: 29 December 2020

Published online: 20 January 2021

\section{References}

1. Chapple LS, Deane AM, Heyland DK, Lange K, Kranz AJ, Williams LT, et al. Energy and protein deficits throughout hospitalization in patients admitted with a traumatic brain injury. Clin Nutr. 2016:35:1315-22.

2. Abdelmalik PA, Dempsey S, Ziai W. Nutritional and bioenergetic considerations in critically ill patients with acute neurological injury. Neurocrit Care. 2017;27:276-86.

3. Foley N, Marshall S, Pikul J, Salter K, Teasell R. Hypermetabolism following moderate to severe traumatic acute brain injury: a systematic review. $J$ Neurotrauma. 2008;25:1415-31.

4. Chapple L-AS, Chapman MJ, Lange K, Deane AM, Heyland DK. Nutrition support practices in critically ill head-injured patients: a global perspective. Crit Care. 2016:20:6.

5. Singer P, Blaser AR, Berger MM, Alhazzani W, Calder PC, Casaer MP, et al. ESPEN guideline on clinical nutrition in the intensive care unit. Clin Nutr. 2019;38:48-79.

6. Dickerson RN, Mitchell JN, Morgan LM, Maish GO, Croce MA, Minard G, et al. Disparate response to metoclopramide therapy for gastric feeding intolerance in trauma patients with and without traumatic brain injury. JPEN J Parenter Enteral Nutr. 2009;33:646-55.

7. Vieira LV, Pedrosa LAC, Souza VS, Paula CA, Rocha R. Incidence of diarrhea and associated risk factors in patients with traumatic brain injury and enteral nutrition. Metab Brain Dis. 2018:33:1755-60.

8. Curry AS, Chadda S, Danel A, Nguyen DL. Early introduction of a semielemental formula may be cost saving compared to a polymeric formula among critically ill patients requiring enteral nutrition: a cohort costconsequence model. Clinicoecon Outcomes Res. 2018;10:293-300.

9. Alexander DD, Bylsma LC, Elkayam L, Nguyen DL. Nutritional and health benefits of semi-elemental diets: a comprehensive summary of the literature. World J Gastrointest Pharmacol Ther. 2016;7:306-19.

10. Hegazi RA, Wischmeyer PE. Clinical review: optimizing enteral nutrition for critically ill patients-a simple data-driven formula. Crit Care. 2011;15:234

11. Cortot A, Phillips SF, Malagelada JR. Gastric emptying of lipids after ingestion of a solid-liquid meal in humans. Gastroenterology. 1981;80:922-7.

12. van Zanten ARH, Petit L, De Waele J, Kieft H, de Wilde J, van Horssen $P$, et al. Very high intact-protein formula successfully provides protein intake according to nutritional recommendations in overweight critically ill patients: a double-blind randomized trial. Crit Care. 2018;22:156

13. Tiengou L-E, Gloro R, Pouzoulet J, Bouhier K, Read M-H, Arnaud-Battandier $F$, et al. Semi-elemental formula or polymeric formula: is there a better choice for enteral nutrition in acute pancreatitis? Randomized comparative study. JPEN J Parenter Enteral Nutr U S. 2006;30:1-5.

14. Heimburger DC, Geels VJ, Bilbrey J, Redden DT, Keeney C. Effects of small-peptide and whole-protein enteral feedings on serum proteins and diarrhea in critically ill patients: a randomized trial. JPEN J Parenter Enteral Nutr U S. 1997;21:162-7.

15. Borlase BC, Bell SJ, Lewis EJ, Swails W, Bistrian BR, Forse RA, et al. Tolerance to enteral tube feeding diets in hypoalbuminemic critically ill, geriatric patients. Surg Gynecol Obstet U S. 1992;174:181-8.

16. Toulouse E, Lafont B, Granier S, Mcgurk G, Bazin J-E. French legal approach to patient consent in clinical research. Anaesth Crit Care Pain Med Fr. 2020;39:883-5.

17. Martindale RG, McClave SA, Vanek VW, McCarthy M, Roberts P, Taylor B, et al. Guidelines for the provision and assessment of nutrition support therapy in the adult critically ill patient: Society of Critical Care Medicine and American Society for Parenteral and Enteral Nutrition: executive Summary. Crit Care Med. 2009;37:1757-61.

18. Kreymann KG, Berger MM, Deutz NEP, Hiesmayr M, Jolliet P, Kazandjiev $G$, et al. ESPEN guidelines on enteral nutrition: intensive care. Clin Nutr. 2006:25:210-23.
19. Leone M, Bouadma L, Bouhemad B, Brissaud O, Dauger S, Gibot S, et al. Hospital-acquired pneumonia in ICU. Anaesth Crit Care Pain Med France. 2018:37:83-98.

20. Spiller RC, Jones BJ, Silk DB. Jejunal water and electrolyte absorption from two proprietary enteral feeds in man: importance of sodium content. Gut. 1987;28:681-7.

21. Jakob SM, Bütikofer L, Berger D, Coslovsky M, Takala J. A randomized controlled pilot study to evaluate the effect of an enteral formulation designed to improve gastrointestinal tolerance in the critically ill patientthe SPIRIT trial. Crit Care. 2017;21:140.

22. Hang C-H, Shi J-X, Li J-S, Wu W, Yin H-X. Alterations of intestinal mucosa structure and barrier function following traumatic brain injury in rats. World J Gastroenterol. 2003;9:2776-81.

23. Tan $\mathrm{M}$, Zhu J-C, Yin $\mathrm{H}-\mathrm{H}$. Enteral nutrition in patients with severe traumatic brain injury: reasons for intolerance and medical management. $\mathrm{Br} J$ Neurosurg. 2011;25:2-8

24. Gentilcore D, Chaikomin R, Jones KL, Russo A, Feinle-Bisset C, Wishart $J M$, et al. Effects of fat on gastric emptying of and the glycemic, insulin, and incretin responses to a carbohydrate meal in type 2 diabetes. J Clin Endocrinol Metab. 2006;91:2062-7.

25. Maerz LL, Sankaran H, Scharpf SJ, Deveney CW. Effect of caloric content and composition of a liquid meal on gastric emptying in the rat. Am J Physiol U S. 1994;267:R1163-1167.

26. Giezenaar C, Lange K, Hausken T, Jones KL, Horowitz M, Chapman I, et al. Acute effects of substitution, and addition, of carbohydrates and fat to protein on gastric emptying, blood glucose, gut hormones, appetite, and energy intake. Nutrients. 2018:10:1451.

27. Hurt RT, McClave SA, Martindale RG, Ochoa Gautier JB, Coss-Bu JA, Dickerson RN, et al. Summary points and consensus recommendations from the international protein summit. Nutr Clin Pract. 2017;32:142S-151S.

28. Wernerman J, Christopher KB, Annane D, Casaer MP, Coopersmith CM Deane AM, et al. Metabolic support in the critically ill: a consensus of 19 . Crit Care. 2019;23:318.

29. Gunst J, Casaer MP. Is protein intake saturated at doses recommended by the feeding guidelines for critically ill patients? Crit Care. 2018;22:230.

30. van Zanten ARH, study group. Response to Gunst and Casaer on the letter to the editor "Is the protein intake saturated at doses recommended by the feeding guidelines for critically ill patients?" Crit Care. 2018;22:330.

31. van Zanten ARH, Elke G. Hydrolysed protein enteral nutrition is not superior to polymeric whole protein feeding with regard to gastrointestinal feeding tolerance and feeding adequacy. Crit Care. 2017;21:232.

32. van Zanten ARH, De Waele E, Wischmeyer PE. Nutrition therapy and critical illness: practical guidance for the ICU, post-ICU, and long-term convalescence phases. Crit Care. 2019;23:368.

33. Preiser J-C. High protein intake during the early phase of critical illness: yes or no? Crit Care. 2018;22:261.

34. Seres DS, Ippolito PR. Pilot study evaluating the efficacy, tolerance and safety of a peptide-based enteral formula versus a high protein enteral formula in multiple ICU settings (medical, surgical, cardiothoracic). Clin Nutr. 2017;36:706-9.

35. de Aguilar-Nascimento JE, Prado Silveira BR, Dock-Nascimento DB. Early enteral nutrition with whey protein or casein in elderly patients with acute ischemic stroke: a double-blind randomized trial. Nutrition. 2011:27:440-4

36. Yeh DD, Johnson E, Harrison T, Kaafarani HMA, Lee J, Fagenholz $\mathrm{P}$, et al. Serum levels of albumin and prealbumin do not correlate with nutrient delivery in surgical intensive care unit patients. Nutr Clin Pract U S. 2018:33:419-25.

37. Taverny G, Lescot T, Pardo E, Thonon F, Maarouf M, Alberti C. Outcomes used in randomised controlled trials of nutrition in the critically ill: a systematic review. Crit Care. 2019;23:12.

\section{Publisher's Note}

Springer Nature remains neutral with regard to jurisdictional claims in published maps and institutional affiliations. 